\title{
From allergy to labial abscess following a bee sting: A Case report
}

\author{
Brunda $\mathrm{M} \mathrm{S}^{1 *}$, Padmini S N ${ }^{2}$, D. Shetty C. ${ }^{3}$, Treesa MD. ${ }^{4}$, Sainath A. ${ }^{5}$ \\ DOI: https://doi.org/10.17511/ijmrr.2020.i03.09
}

\author{
1* Brunda M S, Consultant, Department of Internal Medicine, Aster CMI Hospital, Bangalore, Karnataka, India. \\ 2 Padmini S N, Specialist, Department of Internal Medicine, Aster CMI Hospital, Bangalore, Karnataka, India. \\ ${ }^{3}$ Chaithanya D. Shetty, Junior Resident, Department of Internal Medicine, Aster CMI Hospital, Bangalore, Karnataka, India. \\ 4 Treesa MD, Junior Resident, Department of Internal Medicine, Aster CMI Hospital, Bangalore, Karnataka, India. \\ 5 A. Shannumukha Sainath, Resident, Department of Clinical Pharmacy, Aster CMI Hospital, Bangalore, Karnataka, India.
}

Arthropod bites are a common problem worldwide that are capable of inflicting injury, inciting allergic reactions, and transmitting systemic disease. Members of the Hymenoptera order in particular are of importance as they are nearly ubiquitous in nature and few such as bees, are also used for commercial purposes. These insects have stinging apparatus that deliver venom to the affected tissues during a bite. Hymenopteran venoms contain a mixture of proteins, peptides, and small organic molecules that produce varied effects. Stings from bees, wasps, and ants produce a wide array of clinical manifestations that can be local or systemic. Additionally, these stings may cause life-threatening allergic reactions. Anaphylaxis following a Hymenoptera sting is the most common serious systemic complication. Local reactions can be immediate or delayed. In a few instances, local or disseminated infections have also been reported following bee stings; although very rarely have proved fatal in severe cases. Infection rates are found to be higher in immunodeficiency states. Infections at site of a bee sting can result in the localized pustular lesion with peripheral induration or in severe cases deep necrotizing fascia infection with sepsis and multisystem organ failure. Here we report a case of a bee sting in the upper lip leading to the painful swelling with abscess formation successfully treated with antibiotics, incision, and drainage. Numerous mechanisms for infection in arthropod stings have been described; in our case report, we would like to highlight the importance of timely identification and appropriate management of the infections that may have a significant impact on the overall outcome.

Keywords: Hymenoptera, Bee sting, Anaphylaxis reactions

\section{Corresponding Author}

Brunda M S, Consultant, Department of Internal Medicine, Aster CMI Hospital, Bangalore, Karnataka, India.

Email: brundamysore@gmail.com

\section{How to Cite this Article}

Brunda M S, Padmini S N, Chaithanya D S, Treesa MD, Shannumukha A S. From allergy to labial abscess following a bee sting: A Case report. Int J Med Res Rev. 2020;8(3):269-272.

Available From

https://ijmrr.medresearch.in/index.php/ijmrr/article/ view/1145
To Browse

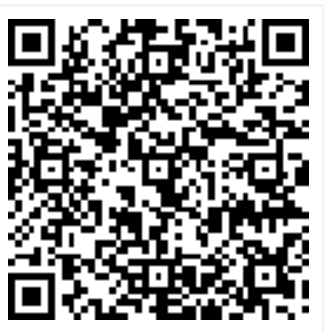

Manuscript Received 2020-05-22

Conflict of Interest No 2020-04-02

Funding

Nil

Review Round 2
2020-04-07
Ethical Approval
Yes

Review Round 3

Accepted 2020-04-12

Plagiarism X-checker $4 \%$

(c) 2020 by Brunda M S, Padmini S N, Chaithanya D. Shetty, Treesa MD, A. Shannumukha Sainath and Published by Siddharth Health Research and Social Welfare Society. This is an Open Access article licensed under a Creative Commons Attribution 4.0 International License https://creativecommons.org/licenses/by/4.0/ unported [CC BY 4.0]. 


\section{Introduction}

Phylum Arthropoda constitutes more than $50 \%$ of the animal species on earth, of which insects, spiders belonging to order Hymenoptera can prove fatal [1].

The three groups of stinging insects under this order belong to the family Apidae (bees), Vespidae (wasps), and Formicidae (ants). These insects are most aggressive when provoked.

They have stinging apparatus at their tail capable of delivering venom [2] stings are of clinical significance in patients allergic to the venom especially in case of multiple stings that can result in death due to anaphylaxis [3].

Most often, it is Type- 1 hypersensitivity reaction and is IgE-mediated. Adrenaline, antihistamines, and steroids are the cornerstones in managing the allergic effects of Hymenoptera venom [4].

Bee venom contains histamine, neurotoxins, vasodilators, and hemolysis. Clinical presentation varies from urticarial pruritic local reaction to severe systemic reaction with erythema, vomiting, diarrhea, generalized swelling, laryngeal edema, bronchospasm, dyspnea, hypotension, and acute renal failure [4]. The symptoms following a bee sting may be immediate or delayed reactions.

Immediate reactions are common, well documented that can be local or systemic reactions manifesting within 2 hours of the bite. Delayed reactions are less common, apparent after 2 hours of the sting. The large local reaction may be delayed reaction with the involvement of entire extremity lasting up to a week.

Here we describe a case with local reaction at the site of bee sting progressing to an infected abscess.

\section{Case Report}

A 50-year-old male patient presented with a history of swelling of upper lip following a bee sting 4 days back associated with wheezing, generalized pruritus for which he had consulted elsewhere and received intravenous steroids and antihistamines.

He developed swelling along the right side vermilion border of the upper lip that progressed over the 4 days to involve the entire upper lip. It was associated with redness, pain, and difficulty in mastication. Despite the initial management with steroids and antihistamines, the swelling had
Increased.

On examination, diffuse firm tender swelling of upper lip involving the vermilion border was noted. The skin and mucosa were stretched, shiny, and erythematous (Figure 1). The rest of the clinical examination was normal.

His blood reports showed elevated C-reactive protein $(24.20 \mathrm{mg} / \mathrm{L})$, neutrophilic predominant leucocytosis (total leukocyte count- 17800/cumm with neutrophils $75.3 \%$ ), Blood culture was sterile.

Computerized tomography imaging of the faciomaxillary region showed soft tissue swelling in the region of the upper lip, measuring $5.9 \mathrm{~cm}$ and soft tissue attenuating contents in bilateral maxillary sinuses suggestive of sinusitis and deviated nasal septum to right with the bony spur.

In view of worsening swelling with tenderness, he underwent upper lip incision and drainage of pus (Figure 2). Examination of pus showed inflammatory cells with gram-positive cocci in pairs and clusters, Methicillin-resistant Staphylococcus aureus (MRSA) was isolated on culture.

The patient was treated with analgesics, antihistamines, and oral Doxycycline $100 \mathrm{mg}$ twice daily for 7 days along with wound care. The swelling gradually reduced in size with good wound healing and the patient is doing well on follow up.

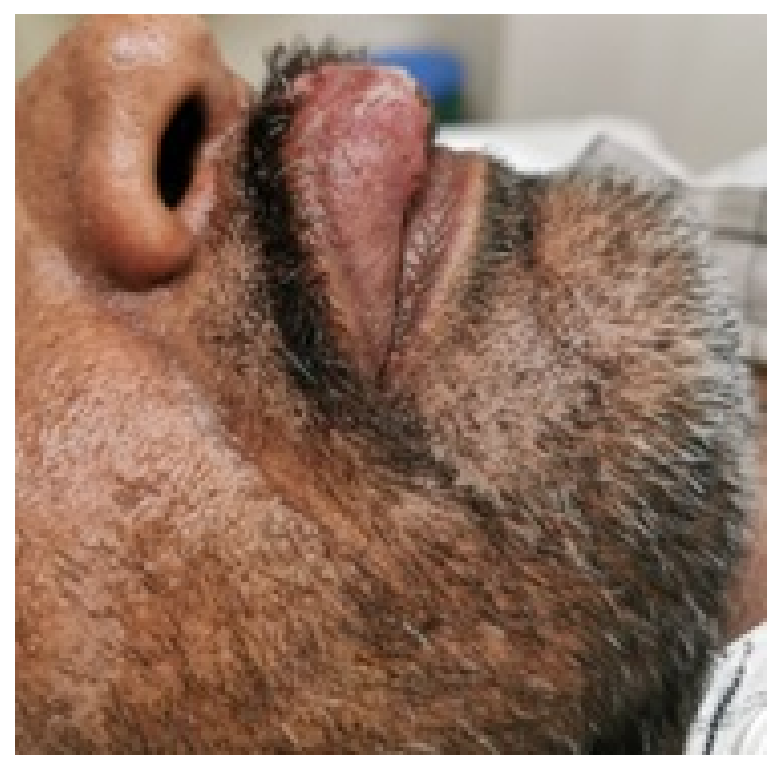




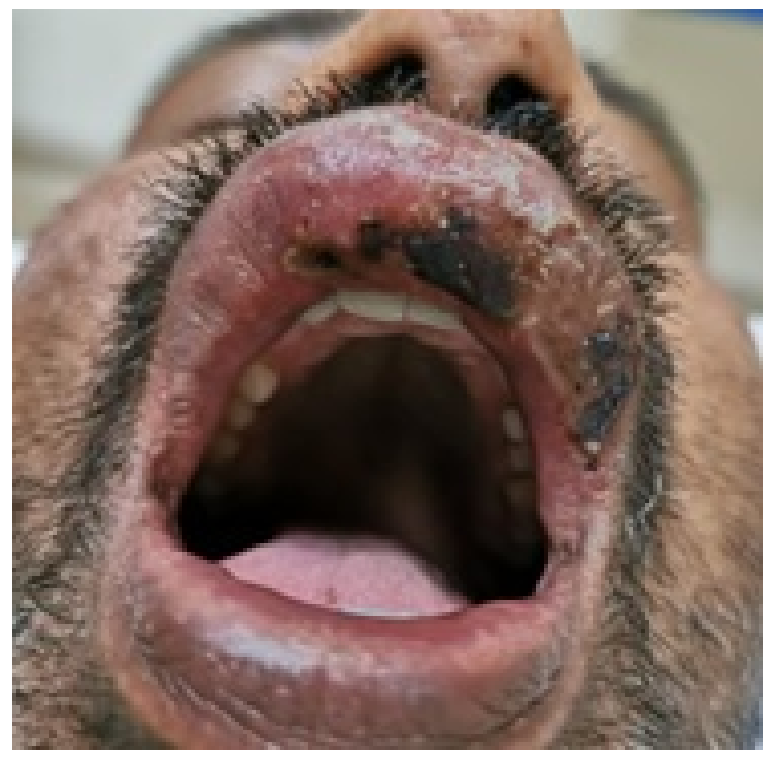

Fig-1: Upper lip swelling with abscess
following a bee sting

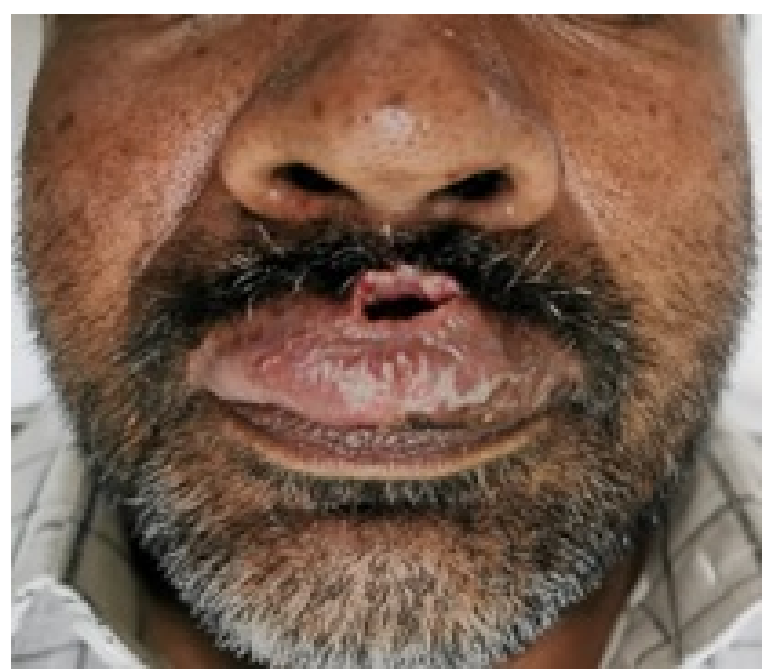

Fig-2: Upper lip incision and pus was drained MRSA was identified on pus culture.

\section{Discussion}

Bee venom is a complex toxin containing a wide array of chemicals including melittin, adolapin, apamin, hyaluronidase, phospholipase $\mathrm{A} 2$, histamine are responsible for local and systemic reaction [5] Peptide mellitin comprising approximately $50 \%$ of the venom has high toxicity causing hemolysis, inflammatory reactions, capillary leak, smooth muscle contraction, membrane disruption and lysis [6]. The severity of the reactions varies according to the individual's response and nature of the incident. Allergic reactions to Hymenoptera stings are common among men; particularly those over 30
Years [7]. A bee sting can lead to a range of atypical reactions that may differ based on the organ system involved like cardiac, renal, muscular, neurological; or local and/or systemic reaction or by the timing of symptoms onset. Myocardial infarction, Acute encephalopathy, conjunctivitis, cataracts, optic neuropathy, acute renal failure, rhabdomyolysis, necrotizing fasciitis, fatal infection and hemifacial asymmetry following Hymenoptera stings are some of the unusual reactions reported [6].

Large local reactions are frequent but rarely dangerous. An epidemiological study revealed that adult male agricultural workers were at greater risk for systemic reactions or large local reactions $[7,8]$. The stinging apparatus may remain in the skin resulting in the formation of foreign body granulomas or, rarely, epidermoid cysts [9]. Additionally, these stings may get infected due to various mechanisms, the infection may be limited with local reaction, abscess formation, and tissue necrosis or may present with systemic manifestations and multiple organ injury secondary to sepsis. Alexander MT et al report a fatal case of necrotizing fasciitis due to streptococcus pyogenes septicemia complicated by multiorgan failure [10].

The exact sequence for infection of a bee sting remains unclear, although many possible mechanisms are suggested. The abdomen of the bee is covered with numerous hairs, mostly branched and plume-like, to which pathogenic bacteria could attach as bees are occasionally attracted by garbage. Secondly, the stinging apparatus is a complex organ that remains deeply embedded in the skin, briskly advancing forward by the alternate thrusts of both lancets while stinging. Meanwhile, the venom is injected from the sac into the victim. Eventually, the entire stinging apparatus detaches from the body of the bee (killing it); however, due to the automatism of intrinsic muscles, the lancets continue to advance, and the venom is continuously pumped. In this manner, any bacteria either on the insect's body or the sting or on the victim's skin surface may get inoculated under the epidermis. Unless carefully removed, the sting remains in the wound facilitating the introduction of infection. Also, the venom contains numerous enzymes and biologically active substances resulting in extensive local swelling, itching that can cause epidermal injury and intradermal implantation of pathogenic bacteria. Furthermore, the edema surrounding the sting site mav temporarily hinder the lymphatic drainage 
Impairing clearance of infection by the immune system $[11,12]$. There can be the varied presentation of infections, Klug et al described a case of 25 years old male presenting with toxic shock syndrome; Staphylococcus aureus was isolated from the pustular lesion at the site of a bee sting and he had recovered well with treatment [13]. Alemán Navas et al reported a rare case of a bee sting in the floor of the nose that mimicked an odontogenic infection. The infected bee sting had resulted in mucosal lysis and lip abscess which responded to incision, drainage, and antibiotic therapy [6]. Derlet RW et al described cases of cellulitis following insect bites at various sites that were treated with broad-spectrum antibiotics. Of note, various organisms are known to cause infections in a case of insect bite but gram-positive cocci such as Streptococcal or Staphylococcus species are most common. Hence appropriate antibiotics that cover these organisms should be administered [14].

There are several reports of infection following Hymenoptera stings, but very few describing local reactions with infection in the anatomic location affected in our patient. Early diagnosis and appropriate management of infection may avert serious local as well as systemic complications due to the infection, like in previously reported cases of necrotizing fasciitis.

\section{Reference}

01. Dongol Y, Dhananjaya B L, Shrestha R K, Aryal G. Wasp venom toxins as a potential therapeutic agent. Protein Pept Lett. 2016;23(8)688-698.

doi: [Article] [Crossref]

02. Ellis AK, Day JH. Clinical reactivity to insect stings. Curr Opin Allergy Clin Immunol. 2005;5(4)349-354.

doi: [Article] [Crossref]

03. Sharmila RR, Chetan G, Narayanan P, Srinivasan S. Multiple organ dysfunction syndrome following single wasp sting. Indian J Peadiatr. 2007;74(12)57-58.

doi: [Article] [Crossref]

04. Junghanss T, Bodio M. Medically important venomous animals- biology, prevention, first aid, and clinical management. Clin Infect Dis. 2006;43(10)1309-1317.

doi: [Article] [Crossref]
05. Kim JH, Kim M, Lee SJ, Han SB, Hyon JY. Corneal bee sting controlled with early surgical intervention and systemic high-dose steroid therapy. Case Rep Ophthalmol Med. 2014. doi: [Article] [Crossref]

06. Alemán Navas RM, Mendoza MG M, Herrera $H$, de Herrera HP. Floor of the nose mucosa lysis and labial abscess caused by a bee sting. Braz Dent J. 2009;20(3)249-253. doi: [Article] [Crossref]

07. David BK, Golden MD. Insect sting anaphylaxis. Immunol Allergy Clin North Am. 2007;27(2)261-268. doi: [Article] [Crossref]

08. Fernandez J, Soriano V, Mayorga L, Mayor M. Natural history of Hymenoptera venom allergy in Eastern Spain. Clin Exp Allergy. 2005;35(2)179-185. doi: [Article] [Crossref]

09. Steen CJ, Janniger CK, Schutzer SE, Schwartz RA. Insect sting reactions to bees, wasps, and ants. Int J Dermatol. 2005;44(2)91-94. doi: [Article] [Crossref]

10. Alexander MT, James DD, Grover MH. Fatal Infection after a Bee Sting. Clin Infect Dis. 2001;32(2)36-38.

doi: [Article] [Crossref]

11. Alemán Navas Ramón Manuel, Martínez Mendoza María Guadalupe, Herrera Henry, Herrera Helen Piccolo de. Floor of the nose mucosa lysis and labial abscess caused by a bee sting. Braz Dent J. 20( 3 )249-253.

Available from: http://www.scielo.br/scielo.php? script $=$ sci_arttext\&pid $=$ S0103-

$64402009000300014 \&$ Ing $=$ en.

https://doi.org/10.1590/S0103-64402009000300014 [Article] [Crossref]

12. Sherman RA. What physicians should know about africanizad honeybees. West J Med. $1995 ; 163(6) 541-546$.

[Crossref]

13. Klug R, Immerman R, Giron JA. Bee bite and the toxic shock syndrome. Ann Intern Med. 1982;96(3)382. doi: [Article] [Crossref]

14. Derlet RW, Richards JR. Cellulitis from Insect Bites- A Case Series. West J Emerg Med Integ Emerg Care Population Health. 2003;4(2). Retrieved from [Article] [Crossref] 